\title{
Sequestration and Storage of Carbon Dioxide Using Hydrate Formation Method in the Presence of Copper Oxide Nanoparticles
}

\author{
V. Montazeri ${ }^{1}$, B. ZareNezhad ${ }^{2 *}$, A. Ghazi $^{1}$ \\ ${ }^{1}$ Department of Chemical Engineering, Razi University, Kermanshah, Iran \\ ${ }^{2}$ Faculty of Chemical, Petroleum and Gas Engineering, Semnan University, Semnan, Iran
}

\section{PAPER INFO}

Paper history:

Received 01 December 2021

Accepted in revised form 19 January 2022

\section{Keywords:}

$\mathrm{CuO}$ nanoparticles

Kinetic

Promoter

Gas hydrate

Carbon dioxide capturing

\section{$A \quad B \quad S \quad T \quad R \quad A \quad C T$}

The nanofluid-based gas hydrate formation process employing copper oxide (CuO) nanoparticles have been experimentally investigated in this work. Different concentrations of nanofluids are injected into the reactor at the operating condition of $29 \mathrm{bar}, 274.15 \mathrm{~K}$, and impeller speed of $100 \mathrm{rpm}$. It was observed that the kinetics of the carbon dioxide hydrate formation process was greatly affected by the nanoparticles. The remarkable point was that at a very low concentration of $20 \mathrm{ppm}$, a considerable improvement on the carbon dioxide hydrate formation kinetic without using any surfactant was obtained. At the concentration of $20 \mathrm{ppm}$, the values of the initial rate of hydrate formation, growth time, and induction time were 0.0495 , 194.5, and $4.4 \mathrm{~min}$, respectively, which these results can be of great importance for the use of carbon dioxide hydrate in various industries. The results indicated that the kinetics of gas hydrate formation was also severely influenced by the impeller speed and initial gas pressure. The rate of $\mathrm{CO}_{2}$ captured in the hydrate crystalline lattice is also modeled by the first-order kinetic model. It was seen that this model can be used to predict the rate of hydrate formation with considerable accuracy.

doi: $10.5829 /$ ijee.2022.13.01.06

\begin{tabular}{|c|c|c|c|}
\hline \multicolumn{4}{|c|}{ NOMENCLATURE } \\
\hline $\mathrm{P}_{0}$ & Initial pressure $[\mathrm{MPa}]$ & $\mathrm{c}$ & $\mathrm{CO}_{2}$ bulk concentration in the liquid phase $\left[\mathrm{mol} . \mathrm{m}^{-3}\right]$ \\
\hline$P_{t}$ & Final pressure $[\mathrm{MPa}]$ & $c_{\mathrm{LG}}$ & $\mathrm{CO}_{2}$ concentration at the liquid-gas interface $\left[\mathrm{mol} . \mathrm{m}^{-3}\right]$ \\
\hline $\mathrm{P}^{*}$ & Equilibrium pressure $[\mathrm{MPa}]$ & $\mathrm{c}_{\mathrm{HL}}^{*}$ & $\mathrm{CO}_{2}$ concentration at the liquid-hydrate interface $\left[\mathrm{mol} . \mathrm{m}^{-3}\right]$ \\
\hline $\mathrm{R}$ & Universal gas constant $\left[\mathrm{J} \cdot \mathrm{mol}^{-1} \cdot \mathrm{K}^{-1}\right]$ & $\mathrm{K}$ & Apparent rate constant $\left[\mathrm{s}^{-1}\right]$ \\
\hline $\mathrm{T}$ & Temperature $[\mathrm{K}]$ & $\mathrm{K}_{\mathrm{D}}$ & Diffusion rate constant $\left[\mathrm{m} \cdot \mathrm{s}^{-1}\right]$ \\
\hline $\mathrm{R}$ & Gas consumption rate $\left[\mathrm{mol} . \mathrm{s}^{-1}\right]$ & $\mathrm{K}_{\mathrm{G}}$ & Growth rate constant $\left[\mathrm{m} \cdot \mathrm{s}^{-1}\right]$ \\
\hline $\mathrm{V}$ & Volume $\left[\mathrm{m}^{3}\right]$ & $\mathrm{K}_{\mathrm{E}}$ & Proportionality constant $\left[\mathrm{MPa} \cdot \mathrm{mol}^{-1} \cdot \mathrm{m}^{3}\right]$ \\
\hline $\mathrm{Z}$ & Compressibility factor & $\Delta \mathrm{t}$ & Time difference $[\mathrm{s}]$ \\
\hline $\mathrm{Z}_{0}$ & Initial compressibility factor & $\left(\Delta \mathrm{n}_{\mathrm{H}}\right)_{\mathrm{t}+\Delta \mathrm{t}}$ & The mole of hydrate formation at time $t+\Delta t[\mathrm{~mol}]$ \\
\hline$A_{L G}$ & Gas-liquid interfacial area $\left[\mathrm{m}^{2}\right]$ & $\left(\Delta \mathrm{n}_{\mathrm{H}}\right)_{\mathrm{t}}$ & The mole of hydrate formation at time $t$ [mol] \\
\hline $\mathrm{A}_{\mathrm{HL}}$ & Solid-liquid interfacial area $\left[\mathrm{m}^{2}\right]$ & $\mathrm{n}_{\mathrm{D}}$ & Amount of carbon dioxide consumed mole in the gas phase [mol] \\
\hline $\mathrm{n}_{\mathrm{c}}$ & Total gas consumed mole [mol] & $\mathrm{n}_{\mathrm{G}}$ & Amount of carbon dioxide dissolved in the liquid phase [mol] \\
\hline
\end{tabular}

\section{INTRODUCTION}

Carbon dioxide has always been mentioned as one of the gases that have led to the phenomenon of global warming.
Therefore, the activities have been increased to remove this acid gas from the environment. Research has shown that considering the advantages of the gas hydrates

\footnotetext{
*Corresponding Author Email: bzarenezhad@semnan.ac.ir

(B. ZareNezhad)
} 
method compared to other methods, it can be used as an effective way to remove carbon dioxide gas. The benefits of the implementation of such a process would be low cost, high safety, and less corrosion [1-3]. To use hydrates in industrial applications, several problems must be solved. Numerous studies have been conducted on the use of surfactants as kinetic promoters in the process of gas hydrate formation [4-6]. Among surfactants, Sodium dodecyl sulfate (SDS) is known as a highly effective kinetics promoter $[4,7]$. But the use of some surfactants leads to the problem of foaming. In some studies, tetrahydrofuran (THF) or tetra-n-butyl ammonium bromide (TBAB) have been used as thermodynamic promoters for reducing the $\mathrm{CO}_{2}$ hydrate equilibrium pressure and enhancing the hydrate formation rate [8-10].

Unfortunately, the thermodynamic promoters occupy some of the hydrate cavities such that the $\mathrm{CO}_{2}$ storage capacity decreases. The liquid foaming and hydrate cavity occupation are major difficulties associated with the use of surfactants [11]. Research has shown that the rate of hydrate formation is substantially influenced by the simultaneous use of SDS and THF [12-14]. Other studies have also shown that the combination of promoters can be more effective [8, 15-18].

Because of the aforementioned difficulties, various studies have been conducted on the gas hydrates formation phenomenon in the presence of nanoparticles. Nanographite is one of these nanoparticles. Research has revealed that these nanoparticles, lead to an increase in the induction time and maximum $\mathrm{CO}_{2}$ consumed mole about 80.8 and $12.8 \%$, respectively $[19,20]$. ZareNezhad et al. [21] investigated the entrapment of carbon dioxide gas using the hydrate method by employing the nonconductive nanographene oxide (NGO) particles for the first time. The remarkable result was that in the presence of $30 \mathrm{ppm}$ NGO, $95 \%$ gas to hydrate formation could be obtained in less than $2.5 \mathrm{~h}$. The effect of three different nanoparticles of multi-wall carbon nanotubes (MWNTs), $\mathrm{TiO}_{2}$, and $\mathrm{SiO}_{2}$ on the hydrate formation process was also examined in another research. The induction time of $\mathrm{CO}_{2}$ hydrate formation was remarkably decreased to $12.5 \mathrm{~min}$ in the presence of $0.005 \mathrm{wt} \%$ MWNTs nanoparticles [22]. Other research has also shown that multi wall carbon nanotubes (MWNTs) can have a significant effect on improving the dissolution of carbon dioxide as well as the hydrate formation process. The presence of MWNTs nanoparticles at optimum concentration led to the improvement of kinetic parameters [23]. Khalili et al. also reported that the adsorption of carbon dioxide on MWNTs is significantly increased in the presence of MWNTs [24].

In the other work, the effect of aluminum oxide and $\mathrm{NGO}$ in the presence of surfactant on the formation kinetics of carbon dioxide hydrate was tested. The results showed that the concentration of $400 \mathrm{ppm}$ NGO and 0.4 wt $\% \mathrm{Al}_{2} \mathrm{O}_{3}$ had the most significant impact on the kinetics parameter of $\mathrm{CO}_{2}$ hydrate formation [25]. Zhou et al. [26] also showed that gas consumption, induction time, and the ratio of water to hydrate conversion were affected by the simultaneous presence of tetra-n-butyl ammonium bromide (TBAB) and graphite nanoparticles (GN). In another work, the effect of iron oxide $\left(\mathrm{Fe}_{3} \mathrm{O}_{4}\right)$ nanoparticles at different concentrations in the simultaneous presence of $400 \mathrm{ppm}$ SDS and $400 \mathrm{ppm}$ cetyltrimethylammonium bromide (CTAB) were investigated. The results showed that at an optimum concentration of $0.15 \mathrm{wt} \%$ the induction time decreased by $70.6 \%$ and the mole of gas consumption increased about $160 \%$ [27]. Bozorgian [28] also studied zinc oxide nanoparticles in the presence of CTAB. The experiments were performed at two concentrations of 0.05 and $0.1 \mathrm{wt} \%$ and the results showed an acceptable effect of these nanoparticles on the storage capacity of $\mathrm{CO}_{2}$ hydrate formation. Additional studies on the effect of nanoparticles in pure form and also in the simultaneous presence of kinetic and thermodynamic promoters on $\mathrm{CO}_{2}$ hydrate formation are summarized in Table 1.

Due to the positive effect that was mentioned for nanoparticles in the process of carbon dioxide hydrate formation, hence the copper oxide nanoparticles to promote the hydrate formation process have been investigated. Of course, various studies have been conducted on the simultaneous use of kinetic and thermodynamic enhancers in the presence of nanoparticles. However, for a more detailed study in this study, pure copper oxide nanoparticles were used. To achieve the best result, different concentrations of nanoparticles at different temperatures and pressures were also tested. To explain the process, a kinetic model is also presented at different nanoparticle concentrations and operating conditions.

Table 1. Nanoparticles used to improve the kinetics of $\mathrm{CO}_{2}$ hydrate formation

\begin{tabular}{lcc}
\hline Nanoparticles & $\begin{array}{c}\text { Kinetic and thermodynamic } \\
\text { promoter }\end{array}$ & Reference \\
\hline $\mathrm{GN}$ & - & {$[19,20]$} \\
$\mathrm{NGO}$ & - & {$[21]$} \\
$\mathrm{MWNTs} \mathrm{TiO}_{2}$, & - & {$[22]$} \\
and $\mathrm{SiO}_{2}$ & & \\
$\mathrm{MWNTs}$ & - & {$[23]$} \\
$\mathrm{AlOOH}$ & - & {$[29]$} \\
$\mathrm{Al}_{2} \mathrm{O}_{3}$ and $\mathrm{NGO}$ & $\mathrm{TBAB}$ & {$[25]$} \\
$\mathrm{GN}$ & $\mathrm{TBAB}$ & {$[26]$} \\
$\mathrm{Fe}_{3} \mathrm{O}_{4}$ & $\mathrm{CTAB}$ & {$[27]$} \\
$\mathrm{ZnO}$ & $\mathrm{CTAB}$ & {$[28]$} \\
$\mathrm{Ag}$ & $\mathrm{SDS}$ & {$[30]$} \\
$\mathrm{GN}$ & $\mathrm{SDBS}$ & {$[19]$} \\
$\mathrm{MWNTs}$ & $\mathrm{TBAB}$ & {$[31]$} \\
\hline
\end{tabular}




\section{MATERIAL AND METHODS}

\section{Compounds used}

To perform the test with high accuracy, the carbon dioxide gas with a purity of $99 \%$ was provided from Sepehr Gas Company. Highly pure, deionized water is also provided from the laboratory. Some of the physical characteristics of the synthesized copper oxide nanoparticles are given in Table 2. Suspension of different concentrations of $\mathrm{CuO}$ nanoparticles are prepared and tested. It should be noted that all chemicals for the synthesis of copper oxide nanoparticles have been prepared by Merck Company.

\section{Synthesis of nanoparticles}

The materials for the synthesis of copper oxide nanoparticles are copper chloride $\left(\mathrm{CuCl}_{2}\right)$, copper nitrate $\left(\mathrm{Cu}\left(\mathrm{NO}_{3}\right)_{2} \cdot 3 \mathrm{H}_{2} \mathrm{O}\right)$, and sodium hydroxide. Initially, 100 $\mathrm{mL}$ of a $1 \mathrm{M}$ solution of copper chloride and copper nitrate is prepared. Then, $1 \mathrm{M}$ sodium hydroxide solution is added dropwise to the solution at room temperature until the $\mathrm{pH}$ reached to 14 . The resulting precipitate is then filtered and washed several times with water and finally ethanol. It is then dried at $16{ }^{\circ} \mathrm{C}$ for 16 hours. Finally, it is calcined for 4 hours at $500{ }^{\circ} \mathrm{C}$ to obtain copper oxide nanoparticles.

The model for the device used for SEM testing is TeScan-Mira III (Czech Republic). As can be seen, copper oxide nanoparticles are spherical and have a diameter between 20-30 nm.

Table 2. Physical properties of nanoparticle

\begin{tabular}{lcccc}
\hline Nanoparticles & Purity & $\begin{array}{c}\text { Diameter } \\
(\mathbf{n m})\end{array}$ & $\begin{array}{c}\text { Density } \\
\left(\mathbf{g} / \mathbf{c m}^{\mathbf{3}}\right)\end{array}$ & $\begin{array}{c}\text { Specific } \\
\text { surface area } \\
\left(\mathbf{m}^{2} / \mathbf{g}\right)\end{array}$ \\
\hline $\mathrm{CuO}$ & $99 \%$ & 20 & 6.4 & 150 \\
\hline
\end{tabular}

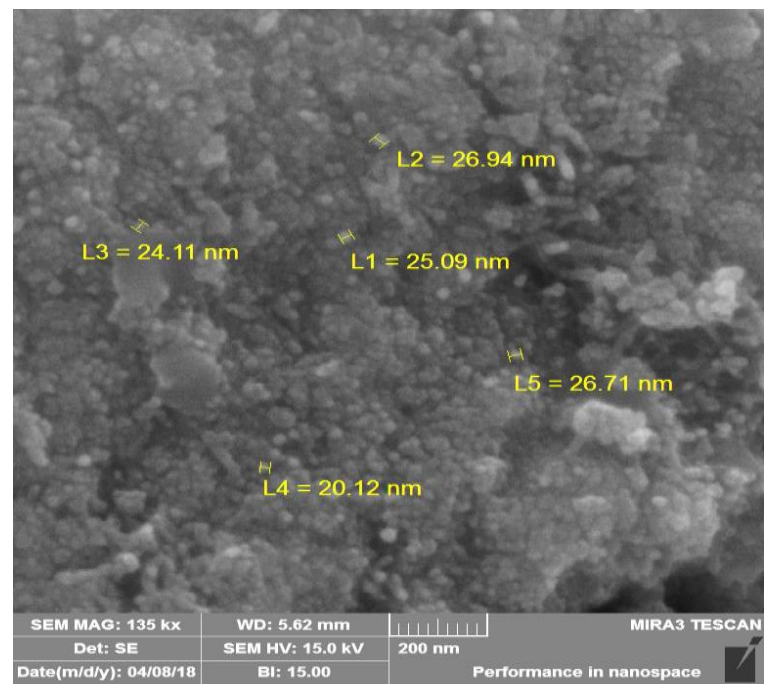

Figure 1. SEM image of $\mathrm{CuO}$ nanoparticles

\section{Apparatus}

The experimental equipment set up used in the hydrate formation process as a unified system is shown in Figure 2. The reactor used in this experiment is a cylindrical container with a thickness of $2 \mathrm{~cm}$ and a volume of 300 $\mathrm{mL}$. The system is also equipped with a vacuum pump, which is used to discharge air and fluid injection into the reactor. A data acquisition system recorded the temperature and pressure of the reactor every $5 \mathrm{~s}$ and stored them on the personal computer. The electric motor is located on the top of the reactor, which is used to rotate the four-blade impeller to fully mix the gas and liquid phases. To control the system temperature and keep the temperature constant at the desired value, the coolant circulator system has been used. Ethylene glycol solution is uniformly pumped inside the jacket covering the reactor. There are also 4 needle valves around the reactor, for injecting and discharging gas and liquid phases.

\section{Procedure}

The nanofluid containing different amounts of $\mathrm{CuO}$ nanoparticles was prepared by using deionized water. To distribute the nanoparticles uniformly in the aqueous phase, the solution was placed in an ultrasonic bath for 5 minutes. Finally, nanofluids with concentrations ranging between 10 to 100 ppm were prepared. Before each test, the reactor was washed twice with deionized water. To discharge the air inside the reactor and inject of suspension into the reactor, a vacuum pump was used.

After the suspension was injected into the reactor, its temperature was set to the desired value by the cooling system. Afterward, by opening the inlet valve of the $\mathrm{CO}_{2}$, the pressure rises to the desired initial pressure. Then, by turning on the motor and adjusting it to the desired number, the impeller rotates inside the reactor and the solution was stirred. As the impellers rotate and the process begins, the gas pressure decreases to eventually reach an equilibrium pressure.

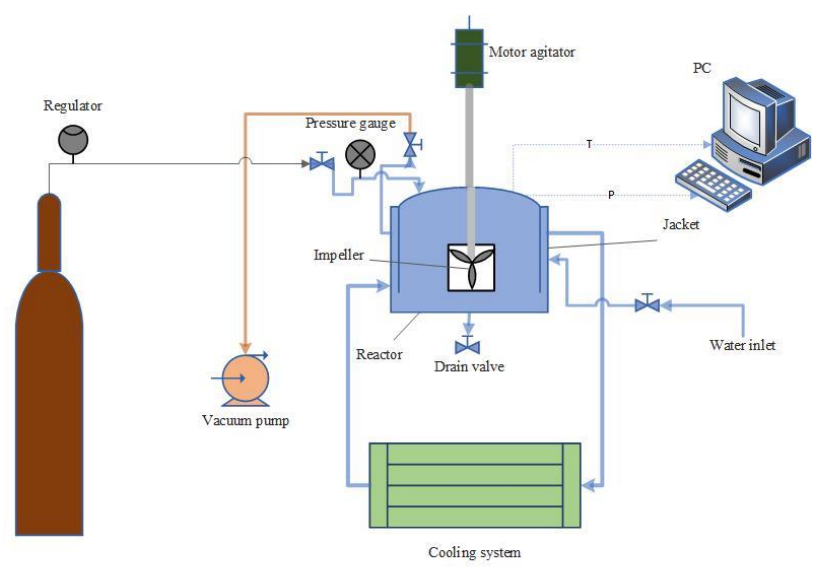

Figure 2. Schematic diagram of an experimental set up used to form the gas hydrate 


\section{Calculation methodology and projected model}

\section{Amount of gas consumed (mole)}

Total moles consumed that trapped in the hydrate lattice is calculated as follows:

$$
\mathrm{n}_{\mathrm{c}}=\frac{\mathrm{P}_{0} \mathrm{~V}}{\mathrm{Z}_{0} \mathrm{RT}}-\frac{\mathrm{PV}}{\mathrm{ZRT}}
$$

$\mathrm{P}, \mathrm{V}$, and $\mathrm{T}$ are used to indicate the temperature, pressure, and volume of the system, respectively. Also, R and Z represent the gas constant and compressibility factor, respectively. In addition, the $\mathrm{Z}$ factor is calculated by the Cubic-Plus-Association (CPA) equation of state considering liquid phase hydrogen bonding effects. The conditions for the beginning and end of the process are specified by subscriptions 0 and end, respectively.

\section{Average rate of hydrate formation}

The forward difference method is used to calculate the average rate of hydrate formation [32]:

$$
\left(\frac{\mathrm{d} \Delta \mathrm{n}_{\mathrm{H}}}{\mathrm{dt}}\right)_{\mathrm{t}}=\frac{\left(\Delta \mathrm{n}_{\mathrm{H}}\right)_{\mathrm{t}+\Delta \mathrm{t}}-\left(\Delta \mathrm{n}_{\mathrm{H}}\right)_{\mathrm{t}}}{\Delta \mathrm{t}}
$$

where $\mathrm{t}$ and $\Delta \mathrm{t}$ indicates time and time difference, respectively. $\left(\Delta \mathrm{n}_{\mathrm{H}}\right)_{\mathrm{t}+\Delta \mathrm{t}}$ and $\left(\Delta \mathrm{n}_{\mathrm{H}}\right)_{\mathrm{t}}$ determines the mole of hydrate formation at time $\mathrm{t}+\Delta \mathrm{t}$ and $\mathrm{t}$, respectively. It should be noted that for every $5 \mathrm{~min}$, the average of these rates is calculated.

\section{Process modeling}

The carbon dioxide gas trapped inside the crystal lattice during the hydrate formation process is calculated by the following equation:

$$
\begin{array}{r}
\frac{\mathrm{dn}_{\mathrm{D}}}{\mathrm{dt}}=\frac{\mathrm{dn}_{\mathrm{G}}}{\mathrm{dt}}=\mathrm{K}_{\mathrm{D}} \mathrm{A}_{\mathrm{LG}}\left(\mathrm{c}-\mathrm{c}_{\mathrm{LG}}\right) \\
=\mathrm{K}_{\mathrm{G}} \mathrm{A}_{\mathrm{HL}}\left(\mathrm{c}_{\mathrm{LG}}-\mathrm{c}_{\mathrm{HL}}^{*}\right)
\end{array}
$$

These equations for diffusion rate $\left(\mathrm{dn}_{\mathrm{D}} / \mathrm{dt}\right)$ and growth rate $\left(\mathrm{dn}_{\mathrm{G}} / \mathrm{dt}\right)$ are given in Equation (3), the constants of which are denoted by $\mathrm{K}_{\mathrm{D}}$ and $\mathrm{K}_{\mathrm{G}}$, respectively. The interfacial area of solid-liquid and liquid-gas is shown with $\mathrm{A}_{\mathrm{HL}}$ and $\mathrm{A}_{\mathrm{LG}}$, respectively and c denotes the $\mathrm{CO}_{2}$ bulk concentration in the liquid phase. It is quite obvious that the amount of carbon dioxide dissolved in the liquid phase $\left(n_{\mathrm{G}}\right)$ is equal to the amount of carbon dioxide consumed mole in the gas phase $\left(\mathrm{n}_{\mathrm{D}}\right)$.

In order to express dioxide concentration at the liquid-gas and hydrate-liquid interface, the parameters of $\mathrm{c}_{\mathrm{LG}}$ and $\mathrm{c}_{\mathrm{HL}}^{*}$ are used. So Equation (2) can be written as follows:

$$
\frac{\mathrm{dn}_{\mathrm{D}}}{\mathrm{dt}}=\frac{1}{\frac{1}{\mathrm{~K}_{\mathrm{G}} \mathrm{A}_{\mathrm{HL}}}+\frac{1}{\mathrm{~K}_{\mathrm{D}} \mathrm{A}_{\mathrm{LG}}}}\left(\mathrm{c}-\mathrm{c}_{\mathrm{HL}}^{*}\right)
$$

Using the pressure of the system, it is possible to express the driving force of the hydrate formation process as follows:

$$
\mathrm{c}-\mathrm{c}_{\mathrm{HL}}^{*}=\frac{\mathrm{P}-\mathrm{P}^{*}}{\mathrm{~K}_{\mathrm{E}}}
$$

where $\mathrm{P}, \mathrm{P}^{*}$ the pressure of the system at instant $\mathrm{t}$, the equilibrium pressure of the system. The proportionality constant of $\mathrm{K}_{\mathrm{E}}$ was used to establish Equation (5).

At the initial $\mathrm{CO}_{2}$ hydrate formation process the diffusion resistance is very small in comparison with growth resistance. So it can be assumed that the growth rate controls the process. So by employing $\left(1 / \mathrm{K}_{\mathrm{D}} \cdot \mathrm{A}_{\mathrm{LG}}\right)=0$ in Equation (4) and combining the result with Equations (1) and (4), the kinetic reaction of $\mathrm{CO}_{2}$ hydrate formation is written as follows:

$$
-\frac{\mathrm{dP}}{\mathrm{dt}}=\frac{\mathrm{ZRTK}_{\mathrm{G}} \mathrm{A}_{\mathrm{HL}}}{\mathrm{VK}_{\mathrm{E}}}\left(\mathrm{P}-\mathrm{P}^{*}\right)
$$

Assuming $\mathrm{K}=\left(\mathrm{RTK}_{\mathrm{G}} \mathrm{A}_{\mathrm{HL}} / \mathrm{V}_{\mathrm{G}} \cdot \mathrm{K}_{\mathrm{E}}\right)$ at the initial time of $\mathrm{CO}_{2}$ hydrate formation. $\mathrm{K}$ is apparent rate constant and optimum values of that at different operating conditions are calculated by minimizing the difference between measured and predicted gas consumed mole.

\section{RESULTS AND DISCUSSION}

\section{Effect of nanoparticles concentration}

The mole of gas consumption versus time during the process of hydrate formation at different concentrations of suspension is shown in Figure 3. The tests were conducted at operating conditions of 29 bars, $274.15 \mathrm{~K}$, $100 \mathrm{rpm}$, and $150 \mathrm{~mL}$ of nanofluid. The initial time of crystallization corresponds to an exothermic sudden peak of temperature. As can be seen, there is an optimum concentration of nanofluids that the highest amount of gas consumption rate and gas consumed mole are observed at this concentration. As can be seen, at concentrations of 20 , better results are obtained compared to other concentrations .The initial average rate of hydrate formation is 0.0495 and 0.019 (mol of gas $/ \mathrm{mol}$ of water.h), respectively for the optimum concentration of nanofluid and pure water. This means that the use of nanoparticles leads to a $156 \%$ improvement in the rate of gas consumption. The phenomenon of mass and heat transfer has a significant impact on the process of gas hydrate formation. Since hydrate formation is an exothermic phenomenon, so during the process of crystal growing, a certain amount of heat is released. So metal nanoparticles with high thermal conductivity can be effective on the heat transfer phenomenon. Various studies have shown that the presence of metal nanoparticles including copper oxide leads to significantly improve the thermal conductivity of water $[33,34]$.

The mass transfer phenomenon between the different phases (gas, liquid, and hydrate phases) has been significantly affected by the specific surface area of the c- 
opper oxide nanoparticles. Other research has shown that the gas hydrate formation kinetics is influenced by the specific surface area of the nanoparticles [35]. The effect of nanoparticles on improving gas absorption on the liquid surface can be explained by the shuttle effect mechanism. The gas molecule is transferred by nanoparticles from the gas-liquid interface to the liquid bulk. Then the nanoparticles were regenerated by desorbing the gas phase component [29].

Consequently, lower concentrations also caused the nanofluid to have little effect on the enhancement of heat and mass transfer coefficient. Also, due to the high bonding properties of nanoparticles at high concentrations, the specific surface area is reduced. So the Brownian motion of nanoparticles is reduced, which leads to a significant reduction of gas consumed moles.

Figure 4 compares the induction and growth times of different concentrations of nanoparticles with pure water. The time from the beginning of the process (Gas injection) until the temperature of the system suddenly increases is defined as induction time. The growth time is also induced by the time between the primary nuclei being formed to the end of the process when the system pressure is constant and reaches to the final value (equilibrium point).As can be seen, the presence of nanoparticles significantly reduced the induction time and growth time, with the greatest effect being observed at a concentration of $20 \mathrm{ppm}$. The average amount of induction and growth times at $20 \mathrm{ppm}$ of nanofluid were 4.4 and $194.5 \mathrm{~min}$, respectively, which decreased by $86.5 \%$ and $42.3 \%$, compared to pure water.

The decrease in the induction time of the system can be stated as follows .Homogeneous and heterogeneous nucleation are two different types of nucleation.

Heterogeneous nucleation occurs when the liquid phase is supersaturated and it should be noted that it is faster compared to other nucleation [36]. Dispersion of nanoparticles inside the liquid phase, lead to increased system inhomogeneity and also provides the environment

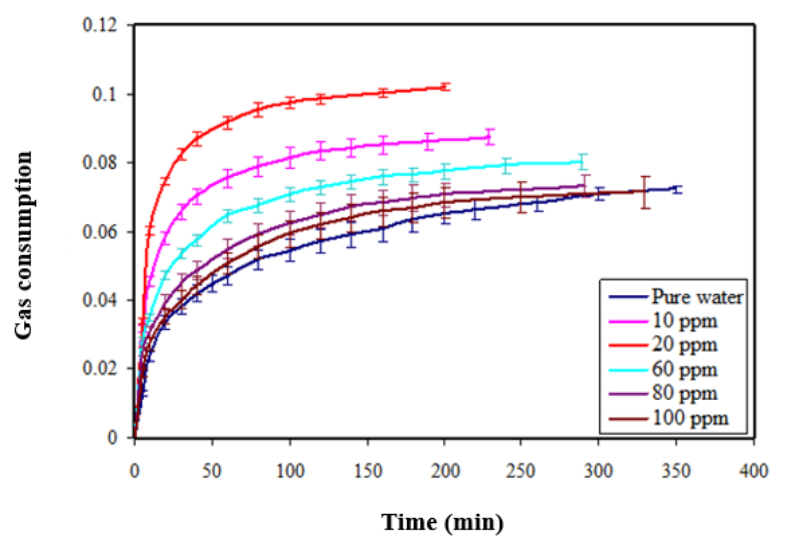

Figure 3. Comparison of gas consumption over time in different concentrations of copper oxide nanofluid for heterogeneous nucleation. Therefore, the induction time in the presence of nanofluid is greatly reduced .On the other hand, in the presence of copper oxide nanoparticles with a high specific surface area, mass transfer between gas-liquid interfaces increases, and consequently growth time decreases.

\section{Effect of initial gas pressure}

Figure 5 shows the effect of different initial gas pressures on the rate of gas hydrate formation at an optimal concentration of $20 \mathrm{ppm}$. As can be seen, the conversion of gas to hydrate is significantly affected by the initial gas pressure. Comparing the rate of gas consumption at different initial pressures, it is observed that the highest rate of hydrate formation is observed pressure at 35 bars pressure and has increased by $123 \%$ compared to the initial pressure of 29 bars. But over time, the amount of hydrate formation rate at different pressures is equal.

The reason for this improvement can be justified by Henry's law. The partial pressure is affected by the initial pressure of the system and increases as it increases, which is the result of increased mass transfer in the system .On the other hand, it is observed that with increasing the initi-

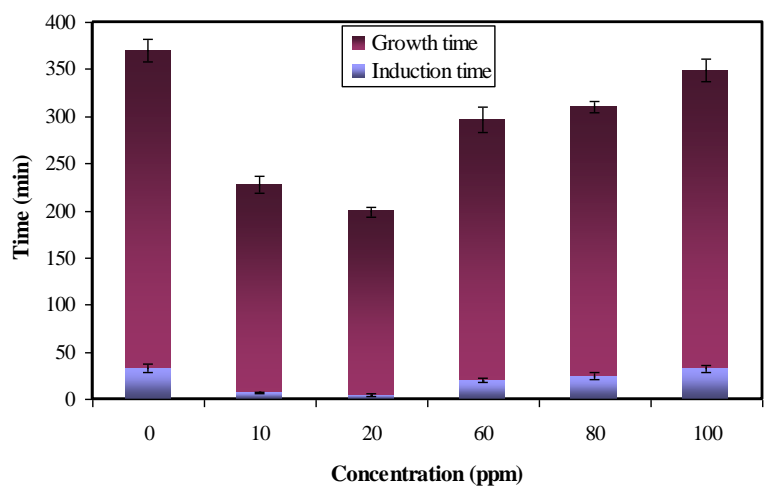

Figure 4. Comparison of induction times and growth of optimum nanofluid concentrations with other concentrations at initial pressure 29 bars and impeller speed of $100 \mathrm{rpm}$

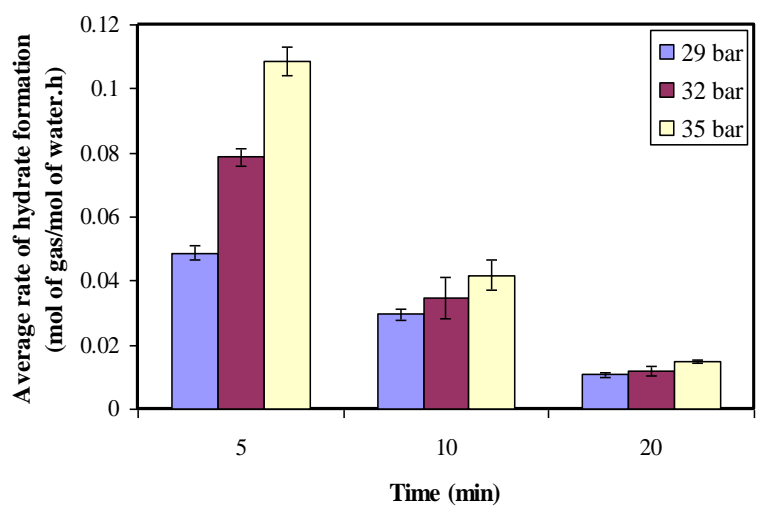

Figure 5. The effect of different impeller speeds on the rate of hydrate formation at the optimal concentration of $20 \mathrm{ppm}$ 
al gas pressure, the effect of nanoparticles on improving the trapping rate of gas inside the hydrate crystal lattice becomes more significant. This level of dependence decreases at lower initial pressures.

Induction and growth times at different initial pressures are compared in Figure 6. According to the results, the induction time is inversely related to the initial gas pressure and decreases with increasing gas pressure The average induction time at concentration $20 \mathrm{ppm}$, at initial pressures of 35,32 , and 29 bars were $0.7,1.8$, and $4.35 \mathrm{~min}$, respectively .Changing the initial pressure of the system from 29 to 35 bars, lead to an $84 \%$ decrease in induction time. Also, when the initial pressure increases to 35 bars, the induction time is reduced by about $90.8 \%$ for pure water .Increasing the system gas pressure leads to an increase in the supersaturation in the liquid phase. Therefore, as the system gas pressure increases, the early nuclei of hydrate are formed earlier, resulting in reduced induction time.

It is observed that at different initial pressures, the presence of nanoparticles reduces the induction time compared to pure water. But it is observed that changes in the initial pressure of the system do not have much effect on growth time.

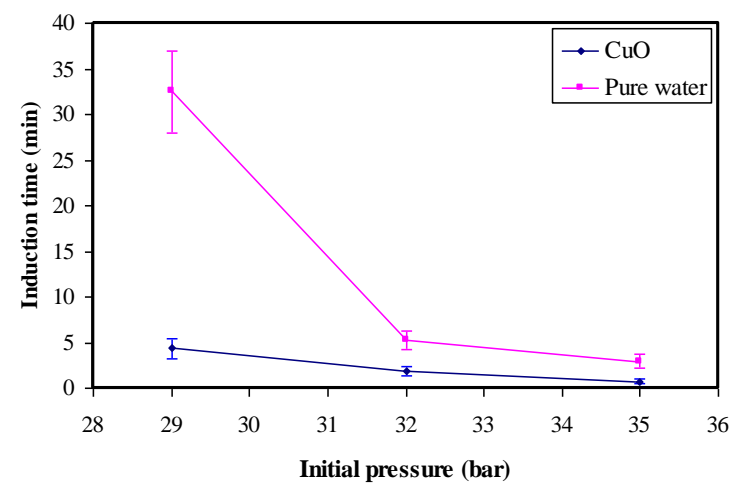

(a) Induction time

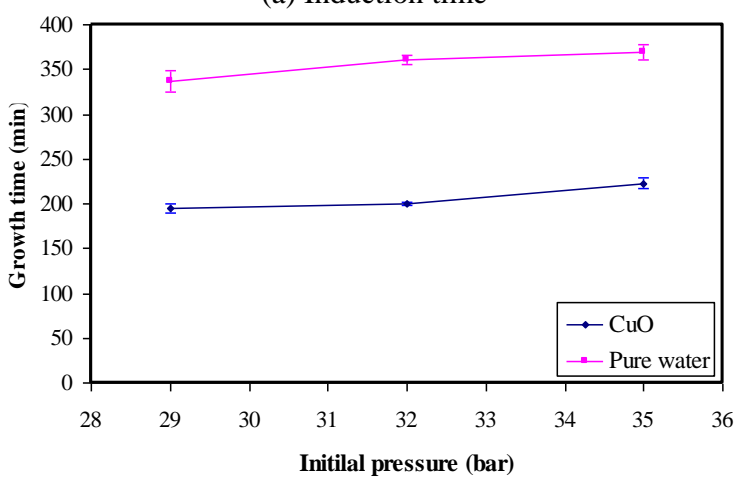

(b) Growth time

Figure 6. Induction time and growth time values for initial gas pressures at an impeller speed of $100 \mathrm{rpm}$ and nanofluid concentration of $20 \mathrm{ppm}$

\section{Effect of impeller speed}

The impact of different impeller speeds, on gas consumption rate at the optimum concentration of nanofluid, is shown in Figure 7 .The initial gas consumption rate for the concentration of $20 \mathrm{ppm}$ and the impeller speed of 50 and $200 \mathrm{rpm}$ were 0.0236 and 0.0891 (mol of gas/mol of water.h), respectively. So, the rate of gas consumption is increased by about $277.5 \%$.In other words, performed on a stirred reactor at an impeller speed of less than $500 \mathrm{rpm}$, the rate of hydrate formation is influenced by impeller speed [37].

As the impeller speed increases, the Reynolds number also increases. The result of these changes is an increase in mass transfer coefficient and consequently higher gas consumption rates.

Different values of induction and growth times at different impeller speeds, for pure water and the optimum concentration of $20 \mathrm{ppm} \mathrm{CuO}$ is shown in Figure 8. As can be seen, the mentioned kinetic parameters are strongly influenced by the impeller speed. The average induction time in the pure water and the $20 \mathrm{ppm} \mathrm{CuO}$ nanofluid were 4 and $1.2 \mathrm{~min}$, respectively. According to the results, when the impeller speed is increased from 50 to $200 \mathrm{rpm}$, the induction time is significantly reduced by approximately $97.5 \%$. On the other hand, according to the results obtained for growth time, it is observed that an increase four times the impeller speed, leading to a reduction of approximately $70 \%$ of growth time.

As the impeller speed increases, the supersaturation in the liquid phase increases too. Therefore, less carbon dioxide concentration is required for the formation of primary hydrate crystals. Also, the mass transfer at the gas-liquid interface is a surface phenomenon that is directly related to the impeller speed and increases as it increases. The results indicate that the impeller speed is inversely related to the induction time and growth time and strongly influences these kinetic parameters.

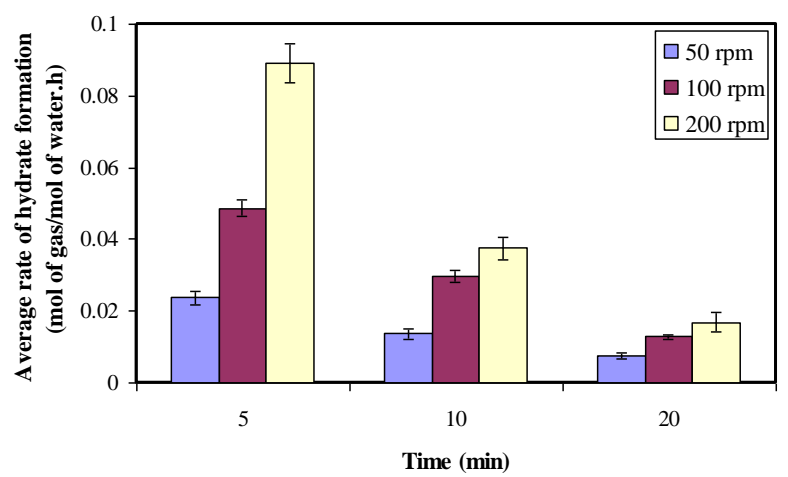

Figure 7. Rate of $\mathrm{CO}_{2}$ consumption at different impeller speeds and in the presence of $20 \mathrm{ppm} \mathrm{CuO}$ nanoparticles 


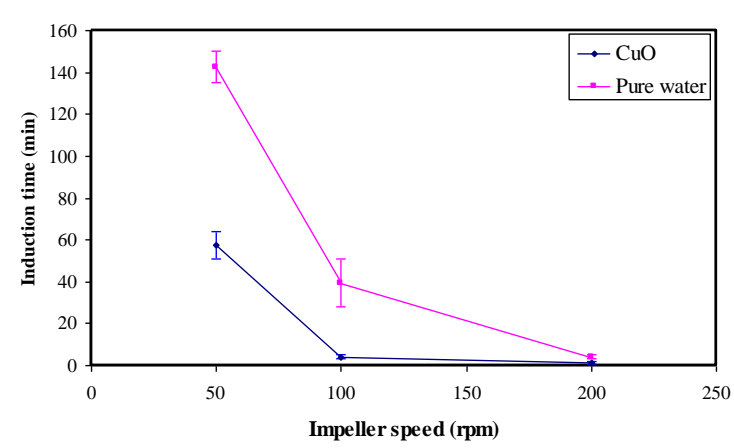

(a) Induction time

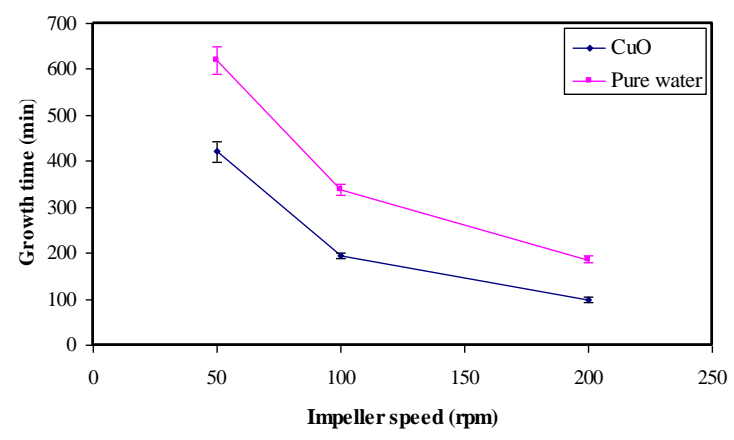

(b) Growth time

Figure 8. Induction and growth time for pure water and $20 \mathrm{ppm}$ of $\mathrm{CuO}$ nanofluid at different impeller speeds and initial pressure of 29 bars

\section{Kinetic model}

The gas hydrate formation kinetic model was first developed by Chun and Lee [38]. Subsequently, other scientists continue to study different kinetic models on the process of gas hydrate formation. In this section, the kinetic model of carbon dioxide hydrate formation under different operating conditions is investigated.

According to the initial slope of the conversion profile, the apparent rate constant $(\mathrm{K})$ can be calculated, the values of which are given in Table 3 . The curves are linear at the beginning of the process but deviate from the linear state over time. The reason for this is the reduction in the number of nucleation sites over time, which results in a reduction in the rate of gas consumption. On the other hand, the driving force decreases over time [25]. According to the results, it is observed that there is a high correlation between the experimental results and the firstorder kinetic model. So that by comparing the results the average absolute deviation (AAD) is less than $1 \%$.

On the other hand, it can be seen that the concentration of nanoparticles in the aqueous phase has a great impact on the apparent rate constant. By increasing the concentration of nanofluids to $20 \mathrm{ppm}$, the value of the apparent rate constant increases and reaches its maximum value .By increasing the concentration, the apparent rate constant decreases and ultimately reaches the minimum value. Brownian motion of nanoparticles in the liquid phase can explain the cause. There are two important resi-
Table 3. Amount of apparent rate constant at the different operating conditions for the nanofluid system and pure water

\begin{tabular}{lcccc}
\hline & $\begin{array}{c}\text { Concentration } \\
(\mathbf{p p m})\end{array}$ & $\begin{array}{c}\text { Initial } \\
\text { pressure } \\
(\mathbf{b a r})\end{array}$ & $\begin{array}{c}\text { Impeller } \\
\text { speed } \\
(\mathbf{r p m})\end{array}$ & $\mathbf{K}$ \\
\hline Pure water & & 29 & 100 & 0.047 \\
$\mathrm{CuO}$ & 10 & 29 & 100 & 0.085 \\
& 20 & 29 & 100 & 0.091 \\
& 60 & 29 & 100 & 0.074 \\
& 29 & 29 & 100 & 0.066 \\
& 100 & 29 & 100 & 0.060 \\
20 & 29 & 50 & 0.048 \\
& 20 & 29 & 200 & 0.150 \\
& 20 & 32 & 100 & 0.106 \\
& 20 & 35 & 100 & 0.127 \\
\hline
\end{tabular}

stances for the penetration of gas into the hydrate crystal lattice, which are the gas-liquid interface resistance and the film around the hydrate crystal. By increasing the concentration to $20 \mathrm{ppm}$, the intensity of the mentioned resistances decreases and reaches its minimum value. But as the concentration of nanoparticles increases, the resistances increase again. Thus the rate of gas penetration is reduced. So it can be concluded, the apparent velocity constant reaches its highest value at a nanofluid concentration of $20 \mathrm{ppm}$.

As can be seen from Table 3, the amount of $\mathrm{K}$ is directly proportional to the initial pressure of the system. An increase in the initial pressure of the system leads to an increase in driving force at the beginning of the process, which results in an improvement in the apparent speed constant.

Increasing the impeller speed also has a significant impact on increasing the apparent rate constant .It is observed that the apparent rate constant is directly related to the impeller speed and reaches its maximum value at $200 \mathrm{rpm}$. As stated, the hydrate formation process is a surface phenomenon. So mass transfer at the gas-liquid interface is significantly affected by the impeller speed.

\section{CONCLUSION}

Copper oxide nanoparticles were investigated as kinetic promoters in the formation of gas hydrates to remove carbon dioxide. Various operating conditions, such as impeller speed and initial gas pressure, have been tested.

It is observed that different kinetic parameters of hydrate formation are significantly improved at optimum nanofluid concentration compared to other concentrations. The optimum concentration for copper oxide nanoparticles is $20 \mathrm{ppm}$ which the average $\mathrm{CO}_{2}$ 
hydrate formation rate is 0.0495 (mol of gas $/ \mathrm{mol}$ of water.h). The values obtained for induction time and growth time were 4.4 and $194.5 \mathrm{~min}$, respectively, which are drastically reduced compared to pure water. The considerable enhancement in gas hydrate formation rate is attributed to the local induced vibrations and excessive heterogeneous nucleation due to the presence of $\mathrm{CuO}$ nanoparticles. In addition, impeller speed and initial gas pressure affect various kinetic parameters during the process of $\mathrm{CO}_{2}$ hydrate formation. As the initial gas pressure increases from 29 to 35 bars, the induction time and average rate of hydrate formation are improved by 20 and $30 \%$, respectively. Also, by increasing the impeller speed by four times, the induction time, growth time, and rate of the gas consumption improve by $97.9,76.7$, and $277.5 \%$, respectively.

The expressed model is employed for an accurate description of the process of $\mathrm{CO}_{2}$ hydrate formation at different operating conditions and nanoparticle concentrations. It was also observed that the presence of copper oxide nanoparticles has a significant impact on the apparent rate constant and reaches its maximum value at optimum nanofluid concentration. It is shown that the CuO-based nanofluid can be successfully employed for the enhancement of $\mathrm{CO}_{2}$ capture rate in gas hydrate-based flue gas recovery processes in the oil and gas industries.

\section{REFERENCES}

1. Ganguly, A. and Ghosh, S., 2011. "A Review of Ventilation and Cooling Technologies in Agricultural Greenhouse Application". Iranian (Iranica) Journal of Energy and Environment, 2(1), pp.3246. 2079-2115

2. Sarshar, M., Esmaeilzadeh, F. and Fathikalajahi, J., 2009. "Study of Capturing Emitted $\mathrm{CO}_{2}$ in the Form of Hydrates in a Tubular Reactor". Chemical Engineering Communications, 196(11), pp.1348-1365. Doi: 10.1080/00986440902900832

3. ZareNezhad, B. and Montazeri, V., 2014. "Development of a High Efficient Gas to Hydrate (GTH) Conversion Process Using SDS Kinetic Promoter for Maximizing the $\mathrm{CO}_{2}$ Recovery with Minimum Energy Consumption”. Energy Conversion and Management, $79, \quad$ pp.289-293. Doi: 10.1016/j.enconman.2013.12.030

4. Kumar, A., Sakpal, T., Linga, P. and Kumar, R., 2013. "Influence of Contact Medium and Surfactants on Carbon Dioxide Clathrate Hydrate Kinetics". Fuel, 105, pp.664-671. Doi: 10.1016/j.fuel.2012.10.031

5. Molokitina, N. S., Nesterov, A. N., Podenko, L. S. and Reshetnikov, A. M., 2019. "Carbon Dioxide Hydrate Formation with SDS: Further Insights into Mechanism of Gas Hydrate Growth in the Presence of Surfactant". Fuel, 235, pp.1400-1411. Doi: 10.1016/j.fuel.2018.08.126

6. Torré, J.-P., Dicharry, C., Ricaurte, M., Daniel-David, D. and Broseta, D., 2011. " $\mathrm{CO}_{2}$ Capture by Hydrate Formation in Quiescent Conditions: In Search of Efficient Kinetic Additives". Energy Procedia, 4, pp.621-628. Doi: 10.1016/j.egypro.2011.01.097

7. Partoon, B., Malik, S. N. A., Azemi, M. H. and Sabil, K. M., 2013. "Experimental Investigations on the Potential of SDS as LowDosage Promoter for Carbon Dioxide Hydrate Formation". AsiaPacific Journal of Chemical Engineering, 8(6), pp.916-921. Doi: 10.1002/apj.1736
8. Joshi, A., Sangwai, J. S., Das, K. and Sami, N. A., 2013. "Experimental Investigations on the Phase Equilibrium of Semiclathrate Hydrates of Carbon Dioxide in TBAB with Small Amount of Surfactant". International Journal of Energy and Environmental Engineering, 4(1), pp.1-8. Doi: 10.1186/22516832-4-11

9. Kim, S., Lee, S. H. and Kang, Y. T., 2017. "Characteristics of $\mathrm{CO}_{2}$ Hydrate Formation/Dissociation in $\mathrm{H}_{2} \mathrm{O}+$ THF Aqueous Solution and Estimation of $\mathrm{CO}_{2}$ Emission Reduction by District Cooling Application". Energy, 120, pp.362-373. Doi: 10.1016/j.energy.2016.11.086

10. Nguyen, N. N., Nguyen, A. V., Nguyen, K. T., Rintoul, L. and Dang, L. X., 2016. "Unexpected Inhibition of $\mathrm{CO}_{2}$ Gas Hydrate Formation in Dilute Tbab Solutions and the Critical Role of Interfacial Water Structure". Fuel, 185, pp.517-523. Doi: 10.1016/j.fuel.2016.08.006

11. da Silva Lirio, C. F., Pessoa, F. L. P. and Uller, A. M. C., 2013. "Storage Capacity of Carbon Dioxide Hydrates in the Presence of Sodium Dodecyl Sulfate (SDS) and Tetrahydrofuran (THF)". Chemical Engineering Science, 96, pp.118-123. Doi: 10.1016/j.ces.2012.10.022

12. Askari Agh Masjed, N. and Pahlavan Zadeh, H., 2019. "Experimental Investigation toward the Kinetic Study of Methane Hydrate Formation in the Presence of THF+ SDS". Iranian Journal of Chemistry and Chemical Engineering, 40(1), pp.261273. Doi: 1021-9986/2021/1/261-273

13. Choi, J. W., Chung, J. T. and Kang, Y. T., 2014. " $\mathrm{CO}_{2}$ Hydrate Formation at Atmospheric Pressure Using High Efficiency Absorbent and Surfactants". Energy, 78, pp.869-876. Doi: 10.1016/j.energy.2014.10.081

14. Torré, J.-P., Ricaurte, M., Dicharry, C. and Broseta, D., 2012. " $\mathrm{CO}_{2}$ Enclathration in the Presence of Water-Soluble Hydrate Promoters: Hydrate Phase Equilibria and Kinetic Studies in Quiescent Conditions". Chemical Engineering Science, 82, pp.113. Doi: $10.1016 /$ j.ces.2012.07.025

15. Ho, L. C., Babu, P., Kumar, R. and Linga, P., 2013. "HBGS (Hydrate Based Gas Separation) Process for Carbon Dioxide Capture Employing an Unstirred Reactor with Cyclopentane". Energy, 63, pp.252-259. Doi: 10.1016/j.energy.2013.10.031

16. Mohammadi, A., Pakzad, M., Mohammadi, A. and Jahangiri, A., 2018. "Kinetics of $\left(\mathrm{TBAF}+\mathrm{CO}_{2}\right)$ Semi-Clathrate Hydrate Formation in the Presence and Absence of SDS". Petroleum Science, 15(2), pp.375-384. Doi: 10.1007/s12182-018-0221-6

17. Mousavi, S. E. and Bozorgian, A., 2020. "Investigation the Kinetics of $\mathrm{CO}_{2}$ Hydrate Formation in the Water System+CTAB+ $\mathrm{TBAF}+\mathrm{ZnO}$ ". International Journal of New Chemistry, 7(3), pp.195-219. Doi: 10.22034/IJNC.2020.121743.1096

18. Yang, M., Liu, W., Song, Y., Ruan, X., Wang, X., Zhao, J., Jiang, L. and Li, Q., 2013. "Effects of Additive Mixture (THF/SDS) on the Thermodynamic and Kinetic Properties of $\mathrm{CO}_{2} / \mathrm{H}_{2}$ Hydrate in Porous Media". Industrial and Engineering Chemistry Research, 52(13), pp.4911-4918. Doi: 10.1021/ie303280e

19. Yu, Y.-s., Xu, C.-g. and $\mathrm{Li}, \mathrm{X}$.-s., 2018. "Evaluation of $\mathrm{CO}_{2}$ Hydrate Formation from Mixture of Graphite Nanoparticle and Sodium Dodecyl Benzene Sulfonate". Journal of Industrial and Engineering Chemistry, 59, pp.64-69. Doi: 10.1016/j.jiec.2017.10.007

20. Zhou, S.-d., Yu, Y.-s., Zhao, M.-m., Wang, S.-1. and Zhang, G.Z., 2014. "Effect of Graphite Nanoparticles on Promoting $\mathrm{CO}_{2}$ Hydrate Formation". Energy \& Fuels, 28(7), pp.4694-4698. Doi: 10.1021/ef5000886

21. ZareNezhad, B. and Montazeri, V., 2016. "Nanofluid-Assisted Gas to Hydrate (GTH) Energy Conversion for Promoting $\mathrm{CO}_{2}$ Recovery and Sequestration Processes in the Petroleum Industry". Petroleum Science and Technology, 34(1), pp.37-43. Doi: 10.1080/10916466.2015.1115872

22. Li, A., Luo, D., Jiang, L., Wang, J. and Zhou, Y., 2019. "Experimental Study on $\mathrm{CO}_{2}$ Hydrate Formation in the Presence of $\mathrm{TiO}_{2}, \mathrm{SiO}_{2}$, Mwnts Nanoparticles". Separation Science and Technology, 54(15), pp.2498-2506. Doi: $10.1080 / 01496395.2018 .1548481$ 
23. Pasieka, J., Jorge, L., Coulombe, S. and Servio, P., 2015. "Effects of as-Produced and Amine-Functionalized Multi-Wall Carbon Nanotubes on Carbon Dioxide Hydrate Formation". Energy \& Fuels, 29(8), pp.5259-5266. Doi: 10.1021/acs.energyfuels.5b01036

24. Khalili, S., Asghar Ghoreyshi, A. and Jahanshahi, M., 2012. " $\mathrm{CO}_{2}$ Separation from Syngas by Multiwall Carbon Nanotube". Iranian (Iranica) Journal of Energy and Environment, 3(1), Doi: 10.5829/idosi.ijee.2012.03.01.0269

25. Hassan, H., Javidani, A. M., Mohammadi, A., Pahlavanzadeh, H Abedi-Farizhendi, S. and Mohammadi, A. H., 2021. "Effects of Graphene Oxide Nanosheets and $\mathrm{Al}_{2} \mathrm{O}_{3}$ Nanoparticles on $\mathrm{CO}_{2}$ Uptake in Semi-Clathrate Hydrates". Chemical Engineering and Technology, 44(1), pp.48-57. Doi: 10.1002/ceat.202000286

26. Zhou, S., Jiang, K., Zhao, Y., Chi, Y., Wang, S. and Zhang, G., 2018. "Experimental Investigation of $\mathrm{CO}_{2}$ Hydrate Formation in the Water Containing Graphite Nanoparticles and Tetra-N-Buty Ammonium Bromide". Journal of Chemical and Engineering Data, 63(2), pp.389-394. Doi: 10.1021/acs.jced.7b00785

27. Firoozabadi, S. R. and Bonyadi, M., 2020. "A Comparative Study on the Effects of $\mathrm{Fe}_{3} \mathrm{O}_{4}$ Nanofluid, SDS and CTAB Aqueous Solutions on the $\mathrm{CO}_{2}$ Hydrate Formation". Journal of Molecular Liquids, 300, pp.112251. Doi: 10.1016/j.molliq.2019.112251

28. Bozorgian, A., 2020. "Investigation of the Effect of Zinc Oxide Nano-Particles and Cationic Surfactants on Carbon Dioxide Storage Capacity". Advanced Journal of Chemistry-Section B, 3(1), pp.54-61. Doi: 10.22034/ajcb.2021.118942

29. Montazeri, V., Rahimi, M. and Zarenezhad, B., 2019. "Energy Saving in Carbon Dioxide Hydrate Formation Process Using Boehmite Nanoparticles". Korean Journal of Chemical Engineering, 36(11), pp.1859-1868. Doi: 10.1007/s11814-0190375-y

30. He, Y. and Wang, F., 2018. "Hydrate-Based $\mathrm{CO}_{2}$ Capture: Kinetic Improvement Via Graphene-Carried-SO ${ }^{3-}$ and $\mathrm{Ag}$ Nanoparticles". Journal of Materials Chemistry A, 6(45), pp.22619-22625. Doi: 10.1039/C8TA08785G

31. Renault-Crispo, J.-S., Coulombe, S. and Servio, P., 2017. "Kinetics of Carbon Dioxide Gas Hydrates with Tetrabutylammonium Bromide and Functionalized Multi-Walled Carbon Nanotubes". Energy, 128, pp.414-420. Doi: 10.1016/j.energy.2017.04.046
32. Pivezhani, F., Roosta, H., Dashti, A. and Mazloumi, S. H., 2016. "Investigation of $\mathrm{CO}_{2}$ Hydrate Formation Conditions for Determining the Optimum $\mathrm{CO}_{2}$ Storage Rate and Energy: Modeling and Experimental Study". Energy, 113, pp.215-226. Doi: 10.1016/j.energy.2016.07.043

33. Abazari Bahnemiri, H., Oloomi, S. A. A., Mirjalily, S. A. A. and Zare-Shahabadi, A., 2021. "The Role of Nanoparticles and Different Tube Diameter on Thermal Performance in Shell and Helically Coiled Tube Heat Exchangers with Single Phase and Sub-Cooled Boiling Flow". Iranian (Iranica) Journal of Energy \& Environment, 12(4), pp.367-377. Doi: 10.5829/ijee.2021.12.04.10

34. Coelho, M., Rivas, M., Vilão, G., Nogueira, E. and Iglesias, T., 2019. "Permittivity and Electrical Conductivity of Copper Oxide Nanofluid $(12 \mathrm{~nm})$ in Water at Different Temperatures". The Journal of Chemical Thermodynamics, 132, pp.164-173. Doi: 10.1016/j.jct.2018.12.025

35. Said, S., Govindaraj, V., Herri, J.-M., Ouabbas, Y., Khodja, M., Belloum, M., Sangwai, J. S. and Nagarajan, R., 2016. "A Study on the Influence of Nanofluids on Gas Hydrate Formation Kinetics and Their Potential: Application to the $\mathrm{CO}_{2}$ Capture Process". Journal of Natural Gas Science and Engineering, 32, pp.95-108. Doi: $10.1016 /$ j.jngse.2016.04.003

36. Kim, J. H., Jung, C. W. and Kang, Y. T., 2014. "Mass Transfer Enhancement During $\mathrm{CO}_{2}$ Absorption Process in Methanol/ $\mathrm{Al}_{2} \mathrm{O}_{3}$ Nanofluids". International Journal of Heat and Mass Transfer, 76, pp.484-491. Doi: 10.1016/j.ijheatmasstransfer.2014.04.057

37. Kumar, A., Khatri, D., Lee, J. D. and Kumar, R., 2016. "Crystallization Kinetics for Carbon Dioxide Gas Hydrate in Fixed Bed and Stirred Tank Reactor". Korean Journal of Chemical Engineering, 33(6), pp.1922-1930. Doi: 10.1007/s11814-016-0040-7

38. Chun, M.-K. and Lee, H., 1996. "Kinetics of Formation of Carbon Dioxide Clathrate Hydrates". Korean Journal of Chemical Engineering, 13(6), pp.620-626. Doi: 10.1007/BF02706029

\section{COPYRIGHTS}

(C)2021 The author(s). This is an open access article distributed under the terms of the Creative Commons Attribution (CC BY 4.0), which permits unrestricted use, distribution, and reproduction in any medium, as long as the original authors and source are cited. No permission is required from the authors or the publishers.

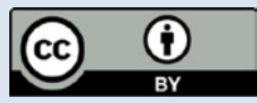

\section{Persian Abstract}

در اين يزوهش فرآيند تشكيل هيدرات كازى مبتنى بر نانوسيال با استفاده از نانوذرات اكسيد مس (CuO (Cu) به طور تجربى مورد بررسى قرار كرفته است.

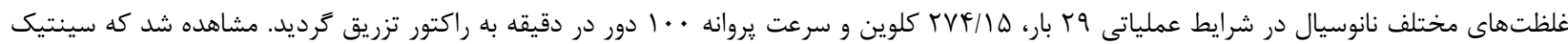

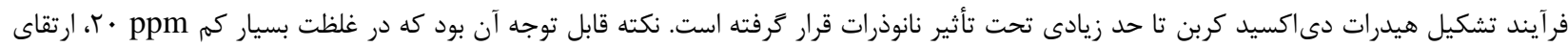

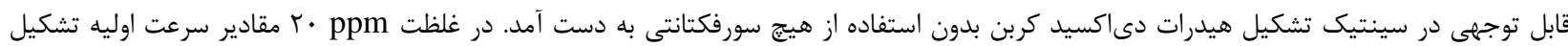

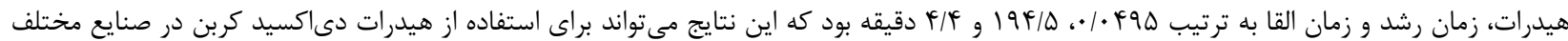

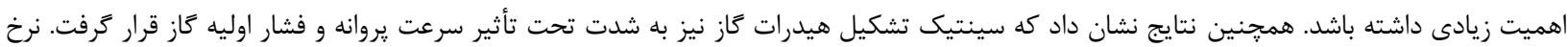

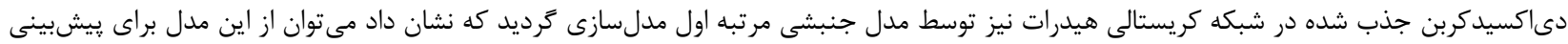
ميزان تشكيل هيدرات با دقتى قابل توجه استفاده نمود. 